\title{
Study of Wuhan Metro Visual Communication Design under the Background of "Jiangcheng Culture"
}

\author{
X. Zhang \\ Wuhan Donghu University \\ Wuhan, China
}

\begin{abstract}
With the rapid urbanization in China, the metro construction of our country's first-tier cities has been under a basic model, and more and more second-tier cities join the metro construction tide. It is found that metro is a very good media platform according to the experiences of varied cities in different countries, all kinds of metro visual culture phenomenon have plentiful social-cultural meanings, metro culture becomes a special cultural landscape of the city. Nowadays, it's a important period for Wuhan, as a city famous for its history and culture in China, to promote its metro construction; how to dig out the essence of "Jiangcheng culture" to apply more cultural charm for Wuhan metro visual communication design and come into contact with the world gradually, has become a subject for us to think and study.
\end{abstract}

Keywords-metro visual communication design; visual culture; “Jiangcheng culture"

\section{INTRODUCTION}

With the rapid urbanization in China, the metro construction of our country's first-tier cities has been under a basic model, and more and more second-tier cities join the metro construction tide. It is found that metro is a very good media platform according to the experiences of varied cities in different countries, the media adventage of metro has been strengthened furtherlly with the continuous extension of metro lines and a sharp increase of urban metro, all kinds of metro visual culture phenomenon have been brought into public focus, these cultural shapes that based on figure, image and video have plentiful social-cultural meanings, metro culture becomes a special cultural landscape of the city.

For those cities with heavy historical and cultural foundation, metro visual culture can extend and improve their visual culture, even improve the contruction and development of urban culture, leading its trend and taste. It's a important period for Wuhan, as a city famous for its history and culture in China, to promote its metro construction; how to dig out the essence of "Jiangcheng culture" to apply more cultural charm for Wuhan metro visual communication design and come into contact with the world gradually, has become a subject for us to think and study.

\section{CurRent Situation of Wuhan Metro Visual COMMUNICATION DESIGN}

The gap of urban metro construction between our country and the developed countries is reduced, but our codes, systems and metro visual communication design that full of art and cultural charms still lag behind our modern metro facilities, the same applies to Wuhan metro visual communication design. Wuhan metro is trying hard to improve the public aesthetic taste and propagate "Jiangcheng culture" of Wuhan City, and has formed its own culture with Wuhan characteristics based on the study of urban metro culture development process at home and abroad. Wuhan metro cultural exhibition such as "Book Metro" and "Display the Future in Metro" is the first case in our country, which has fully embodied the humanistic ideals of Wuhan metro. However, for short history of Wuhan metro construction and imperfect culture penetration in existing metro system design, there are still the following problems:

Firstly, the logo of Wuhan metro consists of three equivoluminal color blocks, standing for this city's regional characteristics, namely "two river intersection and three town split”, however, both the colors and figures of it are very similar to the logo of national inspection exemption and Motorola Corporation, the logo design is of low identification, and lack of culture.

Secondly, as the platform of mass culture, Wuhan metro provides multiple options of culture consumption for the citizens on the surface, but is totally used as a commercial publicity station in essence that based on the consideration of economic and commercial benefits, lack of cultural display obviously.

Thirdly, the content of cultural consumption provided by Wuhan metro management department is simple, mainly consists of commercials, artistic mural and underground sculpture, as well as limited distribution of Metro Daily, mainstream of playing game console, PSP and mobile game in crowded carriage, which affects metro cultural atmosphere badly.

\section{SPECIFIC METHODS OF WUHAN METRO VISUAL COMMUNICATION DESIGN UNDER THE BACKGROUND OF "JIANGCHENG CULTURE"}

\section{A. Making the Best Use of Recognizable Figures and Integrating Underground Space Designs with Ground Space Culture}

As a recognizable information carrier, figures have strong visuality and vision transmission. As a basic element of 
creative expression, figures can transmit the design content and information to the audiences directly, vividly and effectively during visual communication, so as to evoke a strong response in the audiences.

While choosing figures, Jiangcheng characteristics shall be taken into account under the background of "Jiangcheng culture". The most visual chime and landmarks such as Yangtze River Bridge and Wuhan University, can be simplified as abstract figures, and then applied to logo design, advertisement design and public art design of Wuhan metro through varied creative design and expression, combined with different colors and words, so as to highlight the special cultural connotations of Wuhan City.

It is an important way to form the readability of each station that the design of visual works in the underground space shall echo the landmarks on the ground. In this way, designers can design a recognizable figure for each station according to local cultural characteristics, realize "one figure one station, knowing the history of Wuhan City through hundreds of stations", integrate the characteristics of "Jiangcheng culture" into metro space in visual form, so the style and subject of every station can be different from each other, and the passengers can have a clear impression of each station.

\section{B. Refining Line Colors to Reflect the Cultural Features of Wuhan City}

In 1933, the electronic engineer Henry C. Beck applied vivid colors to distinguish the metro lines, set up a new model of modern metro visual communication design. Wuhan metro has followed this model creatively.

Professor Fang Xing of Wuhan University of Technology, the CIS designer of Wuhan Metro Group, said that his inspiration of color selection came from local landscape and culture of each metro station, he led the team to take pictures of the most famous landscape around each line, such as East Lake, Guiyuan Temple and Yellow Crane Tower, found out the most outstanding color and the maximum color block through Mosaic amplification, so as to refined the colors of each metro line. In this way, realized "one color one line, displaying Wuhan features by ten lines" through the threads of urban landscape and cultural information, and the guidance of surrounding culture of each station, with the help of color elements to transmit the cultural connotation of each line color to the passengers. Moreover, how to combine the specific station color with station mark shall be the further study of Wuhan metro line-orientation identification design in the future.

\section{Designing Distinctive Advertisement and Taking the Responsibility for Communicating "Jiangcheng Culture"}

While the metro network construction becoming mature gradually and the arising of "cultural metro" concept, metro advertisement has become the most eye-catching mass media. In the communication process, metro advertisement can create more commercial value and promote the sustain growth for urban economy; meanwhile, it shall take the responsibility for public cultural communication and reveal high cultural quality.
For Wuhan is a famous historical city with more than 3,000 years of culture inheritance, we shall try to integrate the cultural elements of Wuhan city into metro advertisement in metro advertisement design to fully display the city's heavy cultural foundation. Chu opera, for instance, its relevant knowledge and the stage photo of classic characters can be implanted into metro advertisement, to attract the passengers to enjoy it through creative expression. In addition, the advertisements of introducing the city's famous historic and cultural sites, sightseeing, shopping, and recreation shall be set at each station, to make the metro as a "live map" of the city.

In Wuhan metro, “Theme Trains” including "Gourmet Food Train”, "Prestigious School Train” and "Folk Train” can be opened. The metro advertisement shall conform to the subject of that "Theme Trains", for example, series of advertisements of special gourmet food in Wuhan City such as Hot-and-Dry Noodles, Instant Fish Soup Mix and fried Tofu skin can be designed for "Gourmet Food Train", and that of Hanchu Opera, Chu opera and Hubei Drum Art can be designed for "Folk Train", the out-of-town passengers can select different train according to their interests. In this way, the advertising can be more accurate, and the passengers can be more impressed by the internal cultural connotation.

\section{Designing Tourism Products Derived from Metro Marks and Promoting "Jiangcheng Culture" through Visual Communication Design}

The audiences of metro media consist of local citizens and tourists from other places. The special urban culture of metro space shall be displayed to these tourists through more designed products that can be taken away, other than monotonous public art design.

It is feasible to use remarkable Wuhan metro marks as tourism brand image, and then design series of tourism products such as stationery, T-shirt and toys full of publicity and characteristics, as well as small metro map and card that be carried easily, the application of Wuhan metro marks evolves from static symbols into visual symbols that can be moved in varied culture, cities and races all over the world, to promote the communication of "Jiangcheng culture" effectively.

\section{CONCLUSIONS}

All the metro constructions in various countries can't do without national culture. The city's historic cultural tradition and humanistic spirit have been integrated into every urban metro, whether they realized it or not. The citizens have deep feelings for the metro in these cities, and travel by metro almost every day; people are interested in the design of metro station, foreign passengers and artists go there to find their inspiration, all people are looking forward to the new lines, which can give them sensation of new urban culture.

As a newcomer to the urban metro construction, Wuhan doesn't have heavy visual cultural accumulation compared to the foreign cities, so Wuhan metro construction shall focus on the establishment of personality and inherit its special "Jiangcheng culture" nowadays, namely the establishment of unique cultural charm. Following the development of Wuhan metro, its visual communication design shall enrich and 
enlarge the connotation and denotation of "Jiangcheng culture" continuously, to make the citizens and passengers feel the features of Big Wuhan exactly, demonstrate the city's humanistic ideals and outstand its regional culture, so as to break down the space barriers of regional development and realize the optimal development of Wuhan city, and improve the cultural competence of Wuhan City in general.

\section{ACKNOWLEDGEMENTS}

School-level Youth Fund Project of Wuhan Donghu University (2013).

\section{REFERENCES}

[1] Fang Hua, Liu Jianjian. Environmental Visual Design of Hangzhou Metro from the Perspective of Urban Culture [J] Packaging World, May 2013

[2] Xi Xie. Comparative Study on Visual Conveying Design in the Subway of London and Nanjing [J] Hundred Schools in Arts, June 2008

[3] Feng Mingbing. On the Value of Metro Culture from the Perspective of Urban culture[J] Professors’ Lecture, October 2012

[4] Wang Yun. The study of Regional culture in the recognition system of Wuhan metro[J] Home for You, October 2013

[5] Gao Huifang. Study on the Status and Countermeasures of Beijing Metro Culture Construction [J] Journal of Anhui Administration Institute, February 2013 